\title{
ERRATUM
}

Hyun Woo Goo · Dong Soo Suh

\section{Tube current reduction in pediatric non-ECG-gated heart CT by combined tube current modulation}

Published online: 9 May 2006

C) Springer-Verlag 2006

Pediatr Radiol (2006) 36: 344-351

The name of the first author is Hyun Woo Goo.

The online version of the original article can be found at http://dx. doi.org/10.1007/s00247-005-0105-y.

H. W. Goo $(\bowtie) \cdot$ D. S. Suh

Department of Radiology and Research Institute of Radiology, Asan Medical Centre, University of Ulsan College of Medicine,

388-1, Poongnap-2dong, Songpa-gu,

Seoul, 138-736, South Korea

e-mail: hwgoo@amc.seoul.kr

Tel.: +82-2-30104388

Fax: $+82-2-4764719$ 